\title{
Um legado sobre a formação de professores: movimento de interiorização da universidade no Estado da Bahia
}

\begin{abstract}
Resumo: Por meio da análise do Plano Estadual de Desenvolvimento da Economia Baiana (Plandeb) e do Plano Integral de Educação e Cultura (PIEC), além de documentação produzida por intelectuais baianos, principalmente, em jornais, discute-se neste trabalho sobre a formação de professores enquanto aspecto relevante da trajetória histórica de expansão do ensino superior público no Estado da Bahia A ideia de formar professores encontra-se na base desse processo, tanto nas proposições da sociedade civil de interiorização da universidade, quanto nas propostas de efetivação de modelo público estadual. O enfoque metodológico procura dar conta das diferentes dimensões das práticas sociais dos atores envolvidos, enquanto relações de força que circunscreveram a formação do campo universitário do interior baiano. Para tanto, recorre-se á noção de campo, conforme utilizada por Bourdieu, bem como ao estudo das relações de força presentes numa dada situação histórica, de acordo com a concepção presente em Gramsci. Pode-se inferir que a resistência dos setores dominantes à interiorização da universidade, aliada às preocupações de sucessivas gestões estaduais com o tardio desenvolvimento industrial da Bahia, demarcaram as lutas entre diferentes concepções de ensino superior que deveriam ser destinadas ao ambiente interiorano, nas quais estava implicada a questão da formação de professores.
\end{abstract}

Palavras-chave: Ensino superior na Bahia. Política educacional. Movimentos sociais por educação.

\section{Introdução}

O debate sobre a interiorização da universidade no estado da Bahia floresceu no âmbito da sociedade civil a partir da criação da Universidade da Bahia (1946), que passou a ser o grande espelho da modernidade baiana em que parte da intelectualidade e da elite econômica e política interiorana, sonhavam vê-lo refletido em cidades como Feira de Santana, Vitória da Conquista, Ilhéus e Itabuna. Almejavam a extensão da referida universidade para essas cidades e, no avanço dos embates e discussões foram construindo proposições que evoluíam para concepção de projetos próprios, num contexto de crescimento urbano e de ampliação das lutas reivindicativas por oferta educacional em todos os níveis. Naquela situação, enquanto ocorriam movimentações na sociedade civil, nos quadros da administração estadual era elaborado o Plano Estadual de Desenvolvimento da Economia Baiana (Plandeb), em 1959,
Ana Maria Fontes dos Santos Doutora em Educação e professora do Departamento de Educação da Universidade Estadual de Feira de Santana, da área de fundamentos da educação.

Dora Leal Rosa

Doutora em Educação e professora Associada do Programa de PósGraduação da Faculdade de

Educação da Universidade Federal da Bahia. 
previsto para entrar em vigência entre 1960 e 1963. As proposições apresentadas nesse plano de desenvolvimento econômico ajudam a entender a concepção de oferta de ensino superior e sobre universidade, bem como a inserção nesse nível de ensino das discussões pertinentes a formação de professores no estado baiano.

O período de maior efervescência dos embates sobre a interiorização da universidade na Bahia ocorreu a partir da promulgação da Lei de Diretrizes e Bases da Educação Nacional, nº 4.024 de 20 de dezembro de 1961. Quando foram organizadas duas emblemáticas entidades da sociedade civil, agora com o envolvimento maior de intelectuais e políticos da cidade de Feira de Santana: a primeira foi a Fundação Ministro Simões Filho e, a segunda, a Associação Filinto Bastos.

Contudo, além das mudanças e ampliações que a Universidade da Bahia passava depois de 1964, a interiorização do ensino superior no estado da Bahia teve como principal marco estrutural o Plano Integral de Educação e Cultura (PIEC) lançado em 1967, pelo governo estadual, através do qual foram criadas as primeiras faculdades de formação de professores em cidades "estratégicas" do interior baiano. Outro significativo marco que antecedeu o PIEC foi a Lei estadual $\mathrm{n}^{\circ} 1.802$ de 25 de outubro de 1962, que deliberava sobre a criação de faculdades de filosofia (até então, consideradas espaços privilegiados de formação de professores) em seis cidades do interior. Os referidos marcos estruturais refletem momentos históricos distintos da conjuntura política, econômica e educacional, do país e sinalizavam desdobramentos das lutas sobre concepções de formação de professores e de universidade no âmbito das relações de força que resultaram na formação do campo universitário público estadual no interior da Bahia.

A análise empreendida pretendeu compreender os significados das ideias em conflito, nas diferentes situações, daquele contexto da história, pontuando o lugar da formação de professores e os liames e arranjos que articulariam os projetos governamentais resultantes. Confrontado com as propostas da sociedade civil na constituição do campo da educação superior na Bahia, desde o final dos anos de 1950 até os anos de 1970.

Sobre a discussão das relações de força presentes numa dada situação (política, econômica, social e cultural) Gramsci (1984) a desenvolve no estudo das relações entre a estrutura social e a superestrutura. Na análise de uma estrutura social, faz-se necessário 
distinguir os movimentos orgânicos dos movimentos "de conjuntura", argumenta esse autor, são orgânicos, estruturais, os movimentos relativamente permanentes e de amplo alcance histórico. Os elementos de conjuntura, por outro lado, são aqueles "que se apresentam como ocasionais, imediatos, quase acidentais". (GRAMSCI, 1984) Esclarece, contudo, que os elementos de conjuntura dependem de movimentos orgânicos, "mas seu significado não tem um amplo alcance histórico [...]”. (GRAMSCI, 1984, p. 45-46) Gramsci, portanto, chama atenção para que o pesquisador encontre a relação entre o que é orgânico e o que é ocasional, evitando incorrer na falha de apresentar como imediatamente atuantes causas que atuam de modo mediato. (GRAMSCI, 1984, p. 46) Elemento "orgânico" na estrutura social baiana desde os anos de 1950, que se estendeu até a concretização do "milagre econômico", quando a Bahia ingressou no circuito industrial do país, seria a meta dos gestores locais de "resolver" o "enigma", do então escasso, desenvolvimento industrial no território baiano.

Como se verá ao longo deste trabalho, a pesquisa feita revela que, mesmo considerando as especificidades locais, as mudanças na área educacional na Bahia estavam em sintonia com acontecimentos políticos da época e vinculados às mudanças em diversos campos pelas quais o país estava passando, uma vez que Gramsci se refere a situações conjunturais que expressam os próprios movimentos (alguns sísmicos) de superfície da "estrutura" capitalista - no período ocorreu o golpe instituidor da ditadura militar, alterando a articulação dos agentes sociais, que atuavam em diferentes campos e defendiam propostas para a educação na Bahia.

Os conceitos elaborados por Gramsci, contudo, adquirem mais dinamicidade e atualidade quando focalizamos a noção de "campo", elaborada por Bourdieu (1998). Este autor se refere aos diferentes espaços da prática social e esclarece que é em torno de objetivos e práticas específicas que os campos se organizam e apresentam uma lógica própria de funcionamento que estrutura as relações no interior de cada uma deles. Destacamos da teoria de Bourdieu, sobretudo, o aspecto que acentua a constituição das diferenças sociais que tem como princípio a "distribuição das formas de poder". Segundo esse teórico, a abordagem do espaço social como campo implica em reconhecê-lo como um campo de forças e como um campo de lutas, "no interior do qual os agentes se enfrentam, com meios e fins diferenciados conforme sua posição na estrutura do 
campo de forças, contribuindo assim para sua conservação ou a transformação de sua estrutura". (BOURDIEU, 1996, p. 50)

\section{Cenário de debates do ensino superior na Bahia}

Datado do final da década de 1950, o Plandeb é um dos emblemáticos produtos do planejamento científico instituído por administrações baianas para equacionar a questão da estagnação econômica do estado, verificada na primeira metade do século XX, face a consolidação do modo de produção capitalista no país, que vinha desde a Revolução de 1930, com a formação de um parque industrial no Centro-sul. Entretanto a Bahia não acompanhou essa industrialização. Na ocasião, a economia baiana baseava-se na exportação agrícola do cacau. Este se caracterizava como o grande gerador de divisas, mas incapaz de dinamizar a economia estadual, uma vez que os lucros obtidos eram redirecionados para outros mercados. Além disso, a Bahia possuía "um setor comercial e financeiro importante, destacando-se neste último o Banco Econômico", conforme salientam Teixeira e Guerra, (2000, p. 88), porém concentrado na capital do Estado.

Após a queda da ditadura Vargas, no seio das camadas historicamente hegemônicas da burguesia baiana passava-se a reivindicar a industrialização para a Bahia. Essa ação das classes burguesas, de acordo com Guimarães (1982, p. 54) ocorreu "através principalmente da Associação Comercial da Bahia (ACB) e dos Bancos Econômico e da Bahia, no sentido de influenciar e pressionar tanto o executivo quanto o legislativo na busca de soluções convenientes para os problemas 'baianos'”. Iniciando-se, a partir daí, um esforço para o estudo da situação econômica e financeira do estado realizado pelas referidas instituições, às quais se juntariam, na década de 1950, a Universidade da Bahia e a Comissão de Planejamento Econômico (CPE) do governo estadual. (GUIMARÃES, 1982) Esse período de estagnação da economia baiana, em relação ao crescimento industrial do país, caracteriza o que ficou conhecido na literatura econômica como o "enigma baiano".

A implantação das atividades da Petrobrás na Região Metropolitana de Salvador (RMS) em meados da década de 1950 modificou parte desse cenário econômico. As atividades produtivas de extração e refino do petróleo passariam a constituir o fato novo a favor da industrialização na Bahia, motivando a instalação posterior de 
empresas voltadas para o setor petroquímico, constituindo-se em ações essenciais na alteração do perfil agroexportador da economia.

Visto da perspectiva do campo educacional, o impulso mais significativo para equacionar a questão da formação de professores na Bahia ocorreu ainda no Estado Novo, durante a gestão de Isaías Alves à frente da Secretaria Estadual de Educação e Saúde Pública. Na gestão de Isaías tratou-se da implantação do Instituto de Educação da Bahia (um dos importantes monumentos da modernidade baiana, naquele período), com sede própria para formar professores no nível médio, em substituição a antiga Escola Normal da Bahia.

Outro passo de fundamental importância daquela gestão, também no campo da formação de professores foi o projeto de criação da Faculdade de Filosofia da Bahia, em 1941, que seria importante polo de formação, agora em nível superior. ${ }^{1} \mathrm{Na}$ ocasião, aquela unidade de ensino constituía-se no principal núcleo norteador de uma futura universidade, isto é, figurava como obrigatória para se implantar universidade. ${ }^{2}$ A aludida Faculdade de Filosofia foi instalada no prédio da antiga Escola Normal da Bahia, na Rua Joana Angélica, no Bairro de Nazaré, onde permaneceu até o início da década de 1970. Na origem, a instituição constava de quatro seções: Filosofia; Ciências; Letras e Pedagogia, e oferecia 12 cursos. (SENA, 1999 apud SANTOS, 2011) Em 1946, quando da criação da Universidade da Bahia (UBA) essa Faculdade foi uma das unidades iniciais que deram vida à nova instituição.

Nos anos subsequentes à criação da UBA ocorreram desdobramentos na Faculdade de Filosofia, que motivaram o surgimento de importantes institutos e faculdades, entre os quais o Instituto de Matemática e Física (1960), o Instituto de Química (1957), a Faculdade de Educação (1968). No entanto, mesmo com os desdobramentos aí verificados, de resto, era algo que ocorria nas principais universidades brasileiras, como foi o caso da Bahia, em razão da reorganização das ciências e disciplinas a ela articuladas, essas faculdades tiveram papel importante na formação de professores para o ensino médio, desde suas origens.

Criada, portanto, no contexto de mudanças políticas do após queda do Estado Novo, a Universidade da Bahia, ao final da primeira década de existência, experimentou processo de ampliação que a projetaria nacionalmente, tanto do ponto de vista científico, quanto do ponto de vista cultural. Sobretudo neste último aspecto,
(1) A gestão de Isaías Alves seria também tributária da criação da Escola de Agronomia, em Cruz das Almas.

(2) Quando da criação da Universidade da Bahia a legislação para o ensino superior era a mesma do Estado Novo, na qual constava Faculdade de Filosofia como obrigatória para a criação de universidade (abolida com a Lei ${ }^{\circ}$ 4024/1961). 
com a criação de unidades voltadas para as artes e a cultura. Ou seja, movimento significativo de expansão da universidade baiana ocorreria em coincidência com as iniciativas a favor do incremento industrial do Estado, no qual a Petrobrás jogava papel fundamental com a manutenção de convênios e parcerias com essa instituição. (DIAS, 2005)

Portanto, como o incremento das atividades da Petrobras, apenas contribuía para o crescimento econômico concentrado na RMS, pouco reverberava no interior do estado. No campo educacional superior, por exemplo, grande era o contraste entre a capital e o interior apesar dos avanços desse nível de ensino na capital pouco refletia fora desse espaço. Mesmo em cidades médias, tais como Feira de Santana, que se destacava como o principal centro urbano depois da capital, a oferta escolar praticamente concentrava-se na sede do município, e o ensino superior passaria a fazer parte da agenda local de modo efetivo apenas no início dos anos 1970.

Assim, até a metade da década referida, o imenso interior baiano contava apenas com duas instituições de ensino superior voltadas para a área agrícola, de caráter público estadual (uma em Juazeiro e a outra, a Escola de Agronomia de Cruz das Almas, esta incorporada à Universidade Federal da Bahia - UFBA, em 1962). Na Região Cacaueira localizavam-se mais três faculdades particulares, as seguintes: Faculdade de Filosofia, de 1961, em Itabuna, onde seria também implantada em 1967 a Faculdade de Ciências Econômicas e, em Ilhéus existia a Faculdade de Direito, que entrou em funcionamento em 1961.

\section{Interiorização do ensino superior e a formação de professores}

No período estudado, o primeiro desenho de políticas públicas para a educação superior na Bahia aparece traçado no Plandeb, tratava-se de documento elaborado com a intenção de orientar as políticas públicas para todos os setores da economia. Para os objetivos deste trabalho nos debruçamos no conteúdo do tópico referente ao ensino superior. Nele aparece expresso tanto a dimensão do conflito que significava para as elites da Bahia, as proposições interioranas de criar cursos superiores fora dos limites da capital, bem como a concepção pragmática e utilitarista de ensino superior 
(e de educação em geral) para atender as necessidades imediatas de consolidação do capitalismo no estado.

Encontra-se no Plandeb uma referência à criação da "universidade rural" na Bahia, que teria como objetivo formar técnicos em agropecuária. A instituição deveria reunir os cursos então vinculados à Secretaria Estadual de Agricultura oferecidos nas Escolas de Agronomia de Cruz das Almas e na de Medicina Veterinária, localizada em Salvador. Conforme justifica: "o plano centra os esforços e recursos estaduais para equipar mais convenientemente as duas unidades de ensino superior que o estado mantém e são diretamente ligadas para a formação de técnicos de notória participação na vida econômica", pois se pretendia usar a educação como "engrenagem com o propósito deliberado de transformação estrutural que o desenvolvimento requer" ((BAHIA, 1950, p. 51).

Da leitura do Plandeb é possível inferir que se desejava deter qualquer tipo de mudança educacional voltada à população dos municípios interioranos. No diagnóstico sobre a situação do ensino superior, expõe o texto, que a população baiana seria "no País a mais saudosista dos antigos títulos de nobreza dos tempos coloniais", e por essa razão os substituíra pelos títulos universitários. A "prova" disso estava nos "movimentos reivindicatórios de novas faculdades particulares de Direito e Filosofia" (como os que ocorriam nos municípios de Ilhéus e Itabuna), pois, tais cursos, de acordo com o documento, eram buscados como um instrumento de prestígio e não "como um instrumento de habilitação profissional" - mediante a explicitada concepção de modernização econômica (p. 45). Neste sentido, os interesses interioranos em defesa da implantação de faculdades "tradicionais" seriam aí vistos como "um desserviço social", pois, argumenta, "desviaria" os jovens "de carreiras técnicas e de funções úteis", que representaria um "excedente desnecessário [ao "desenvolvimento"] de formados nessas áreas". Para fazer frente a isso, sugere que, "uma rigorosa política universitária está a se impor que ponha cobro a semelhantes despropósitos de criação descontrolada e injustificada de tais faculdades". ((BAHIA, 1950, p. 47) De modo enfático esclarece sobre a necessidade de "rebater o prestígio do ensino falsamente acadêmico e reorientar a vida acadêmica no sentido instrumental que convém ao desenvolvimento" (p. 46). Nessa perspectiva "instrumental" estão, portanto definidas as prioridades das aplicações no setor educacional: 
Ensino primário: Verificada a impossibilidade de aproveitamento [no projeto desenvolvimentista] de toda a população em idade escolar, urge uma política inteligente de rigoroso atendimento das zonas de prioridade [ ... para] o município da capital [... cumpre] o atendimento de toda população escolarizável e em zonas urbanas interioranas, para as quais se prove idêntica política.

Ensino Médio: Conhecida a procura por ensino secundário pelas classes sociais de melhor situação econômica [...], compete ao poder público $[\ldots]$ a derivação de seu maior interesse para o incremento do ensino técnico-profissional, utilizando, mesmo, a grande solicitação para criação de ginásios no Interior num sentido favorável à criação de escolas técnicas de grau médio

Ensino Superior: [...] investir naqueles ramos do ensino superior que por seu caráter técnico tem imediata e fecunda utilização social e econômica […]. (BAHIA, 1950, p. 52)

Não se pode negar que naquele começo de década a Universidade da Bahia já havia iniciado este ajuste com os convênios que estabeleceu com a Petrobras. Daí a importância da continuidade de investimentos tanto federais como estaduais nessa instituição, nas áreas consideradas estratégicas ao desenvolvimento industrial do estado. Posto que o interesse fosse o de "vincular mais estreitamente a Universidade [da Bahia] à vida econômica de nossa comunidade, especialmente contribuindo a emprestar à pesquisa científica um caráter instrumental". (BAHIA, 1950, p. 50)

No tocante à formação dos professores, para o cumprimento das metas para educação nos outros níveis previa-se a "adaptação e aperfeiçoamento do professorado", que significava "utilização do professor como elemento de mudança", que deveria ser conseguida através "do conveniente esclarecimento ideológico que the dê a plena consciência como agente de educação numa sociedade em mudança". (BAHIA, 1950, p. 50) Para efetivar tal intento:

A Secretaria de Educação poderá, em colaboração com o Programa de Educação, Pesquisa e Cultura da C.P.E., utilizar o Centro de Estudos e Aperfeiçoamento do Professor (CEEAP), bem como o Centro de Áudio-Visuais, recentemente criado, para essa urgente tarefa de aperfeiçoamento do professorado, que é o proporcionar ao professor, mediante Campanhas de esclarecimento e cursos específicos, a plena consciência da missão que lhe compete. (BAHIA, 1950, p. 52) 
A ênfase aqui dada do texto dos planejadores baianos, enquanto sujeitos sem muita representatividade na arena política, (já que o Plano fora rejeitado na Assembleia Legislativa), nos serve para visualizar tanto um conceito sobre política educacional para a população (esta entendida como massa de manobra), quanto um pensamento sobre os usos da educação, que seria aprimorado no período seguinte, já na ditadura militar. Por outro lado, vale salientar que o conteúdo do Plandeb, longe de ser um pensamento conservador como parece à primeira vista, ao contrário, pois, na época essas ideias eram tidas como inovadoras e compartilhadas pela esquerda política no Brasil (posto que, acreditava-se, tratar de uma "etapa" histórica a ser cumprida, rumo à superação do capitalismo).

Todavia, a discussão sobre a citada Universidade Rural não passou em branco naquela casa, os indícios revelam que se perceberia a mesma como sendo exequível. Claro está que a lógica enviesada do texto do Plandeb não coincidiria diretamente com os interesses dos diversos setores políticos e sociais em palco, porém algo que figurava como uma espécie de detalhe naquele plano teve desdobramentos inesperados. Pois, tanto na Região Sul do estado, quanto na Região de Feira de Santana já existia movimentos a favor da interiorização da universidade e a ideia dos planejadores estaduais sobre Universidade Rural apenas abria brechas para a ampliação do debate. (SANTOS, 2011) Os indícios encontrados nesta pesquisa apontam que as lideranças de Feira de Santana saíram na frente.

Assim, nos primeiros dias de março de 1962, o Jornal da Bahia, na sessão "Jornal dos Municípios" publica a seguinte manchete: "Feira de Santana será sede: Universidade Rural" - referindo-se a pronunciamento do deputado Clodoaldo Campos na Assembleia Legislativa, que contestava parecer da Secretaria de Agricultura do Estado de que a citada Universidade deveria localizar-se em Salvador. (FEIRA DE SANTANA..., 1962) A partir daí, em sucessivas edições do jornal Folha do Norte, de Feira de Santana, o assunto é tratado com entusiasmo, a princípio, enquanto bandeira de políticos e intelectuais locais. Contudo, a tessitura dessa proposição de Universidade Rural, contida no Plandeb, envolveria âmbitos mais variados de protagonismo.

O ambiente político, no tocante ao contexto educacional brasileiro, era o de embates políticos em torno da aprovação da Lei n 4.024 de 20/12/61, de Diretrizes e Bases da Educação Nacional, bem como, na esteira das lutas por reformas sociais, brotavam as 
discussões sobre reforma universitária, cuja resposta mais imediata foi a criação da Universidade de Brasília - com projeto pedagógico diferenciado e estrutura organizativa mais dinâmica e moderna em relação às universidades brasileiras existentes. Outro diferencial, naquele ambiente da história, seria a crítica à educação brasileira e, em particular, à universidade, tecida pelo movimento estudantil, através da União Nacional dos Estudantes (UNE) e localmente pela União dos Estudantes da Bahia (UEB), composta por universitários e estudantes secundaristas.

Na ocasião, os universitários da UBA estavam bem mobilizados, sobretudo a partir da greve ocorrida em meados de 1960, cuja pauta inicial centrada em problemas da assistência aos estudantes, evoluindo para questões sobre a estrutura da universidade, que incluíam a ampliação do acesso e a questão da qualidade do ensino. Essa greve repercutiu "na opinião pública [nacional] e nos altos escalões do governo e das autoridades educacionais brasileiras". (BRITO, 2008, p. 38) Algo que ampliaria na mesma proporção o prestígio da União dos Estudantes da Bahia no ambiente político local e no movimento estudantil nacional. Inclusive porque este evento provocou o desgaste do Reitor Edgard Santos, que pretendia continuar, no ano seguinte, à frente da instituição, mas, embora referendado por seus pares (encabeçava a lista tríplice encaminhada ao Presidente da República) fora substituído por Albérico Fraga (o segundo nome da lista). A "constituição de um grupo de trabalho" foi um dos pontos de negociação para o final da greve (BRITO, 2008, p. 32), que constituído, assumiria relevância, já na administração de Fraga, a partir da promulgação da Lei nº 4024/61 e da constituição da Universidade de Brasília - esta como novidade institucional, que, para sua implantação, arregimentou número considerável de professores da UBA e outras universidades brasileiras.

Nessa atmosfera, dois eventos estudantis singulares e com repercussões mais amplas, sobretudo no campo educacional, ocorreriam na capital baiana no início da década de sessenta. Foram eles: o Primeiro Seminário Latino-Americano de Reforma e Democratização do Ensino Superior, em 1960 (período em que a UNE agregava-se mais em torno de representantes com perfil de esquerda e já defendia plataformas nacionalistas e de interesses populares); e o I Seminário Nacional de Reforma Universitária, entre os dias 20 e 27 de maio de 1961. 
Portanto, para além do debate que circulava na sociedade brasileira sobre a democratização do ensino em geral protagonizado pela defesa da educação pública, em oposição ao ensino privado, que pontuava as discussões sobre a LDB, na Bahia era constituído um embate particular em torno de questões sobre a educação superior.

Assim, o Plandeb seria apenas um rastilho que acenderia a discussão sobre a demanda de expansão e democratização do ensino, que se propagava nos movimentos da sociedade civil. Naquela situação histórica estavam dadas as condições para se criar uma entidade preocupada com a expansão do ensino superior, que na agenda da época significava, principalmente, interiorizar a universidade. Criar a Fundação Ministro Simões Filho foi a resposta imediata que alguns professores da UBA e da Escola Bahiana de Medicina encontrariam para tentar responder a essas reivindicações.

\section{Fundação Ministro Simões Filho}

A Fundação Ministro Simões Filho, criada no início de 1962, foi a primeira entidade da sociedade civil que elaborou proposta de universidade multicampi para a Bahia, prevista para cobrir as principais regiões do Estado. ${ }^{3}$ Liderada por Jorge Calmon, que dispunha de uma visão privilegiada: tanto na posição de diretor do jornal A Tarde, cuja linha editorial defendia a aprovação integral do Plandeb (GUIMARÃES, 1982, p. 84-85), acompanhava, portanto, de perto as discussões do legislativo baiano e tinha noção do conteúdo exato do texto acima focalizado; bem como na condição de professor da Faculdade de Filosofia e por participar do citado "grupo de trabalho" dedicado a pensar a reestruturação da UBA. A referida "fundação" assume, portanto, a contenda desenrolada no legislativo sobre a ideia de universidade rural com sede localizada no interior e redefine a concepção de educação posta no Plandeb, ao trazer para a arena dos debates a questão da formação de professores.

A discussão aparece elaborada de modo sistematizado no documento intitulado Interiorização da Universidade, ${ }^{5}$ cuja redação é atribuída a Jorge Calmon, também publicado parcialmente no jornal A Tarde, na edição do dia 17 de março de 1962, por ocasião da apresentação à comunidade de Feira de Santana do conteúdo do referido documento. O título da matéria publicada, Feira de Santana quer ter em 1963 Faculdade de Filosofia, já exibe a dimensão do caminho tomado para propor e dar início à interiorização: pela
(3) Desenho dessa possível Universidade foi divulgado nos jornais Folha do Norte (03/03/1962) e Jornal da Bahia (11/03/1962).

(4) Tratava-se apenas de uma associação, todavia, é possível inferir que ao optarem pela denominação de fundação os intelectuais envolvidos não o fariam por acaso, vez que a $L D B$ colocava essa pessoa jurídica como uma das formas para a criação de universidades.

(5) Original desse documento encontra-se no acervo particular de Fernando Pinto. 
via da formação de professores. Assim, para equacionar a escassez da oferta educacional para o interior baiano, o grupo da Fundação Simões Filho descreve sua estratégia da seguinte forma:

O trabalho de interiorização do ensino universitário tem de conhecer como sua primeira fase a criação de escolas de formação de professores secundários, vale dizer Faculdade de Filosofia, Ciências e Letras, onde se produzam docentes em condições de preparar devidamente os pretendentes às futuras escolas superiores de caráter profissional, docentes que levem para os ginásios e colégios [...] a competência em cada matéria, e os métodos educativos que facilitam e torna mais rendosa, hoje, a aprendizagem. (p. 8)

Posto que a perspectiva de avanço da oferta educacional, "dentro de algum tempo, [é] a fundação da Universidade do Interior, órgão cuja sede, seria em Feira de Santana". (p. 3). De acordo com o jornal Folha do Norte (Ed. n ${ }^{\circ} 2747$, de 03/03/1962) a referida universidade abrangeria, inicialmente, além de Feira de Santana, as cidades de Jequié, Vitória da Conquista e Juazeiro.

A base da argumentação sustenta-se na questão do "direito social à educação nos seus vários graus a toda população e não somente a uma fração dela, beneficiada pelas circunstâncias de viver dentro dos limites das capitais". (p. 3). Portanto, o reconhecimento do direito dos baianos à educação, segundo o documento seria a base ou "convicção" que mobilizou "um grupo de professores e profissionais liberais, médicos especialmente, $[\ldots]$ para trabalhar pelo presente movimento". (p. 3). Depreende-se da leitura, que na visão dos protagonistas a ampliação da oferta escolar, pensada a partir da formação de professores, não seria algo em desacordo com o "desenvolvimento", ao contrário só iria beneficiá-lo (p. 7 -8). Todavia, naquele contexto, sobretudo no campo econômico quanto no campo cultural, não haveria espaço para converter as ideias dos intelectuais da Fundação Simões Filho em políticas públicas. A ideia referente à necessidade de formar professores antes de qualquer projeto para formação de técnicos, somente será contemplado em etapa posterior, no PIEC, já sob a ditadura militar, como veremos mais adiante.

Outro legado extraído das proposições do texto Interiorização da Universidade foi o de os próprios professores da Faculdade de Filosofia da Universidade da Bahia, signatários do documento, 
advogar o status e o espaço profissional do "professor licenciado" ao exigirem a ampliação da oferta dos cursos nela oferecidos ao interior. Como se pode depreender do texto:

[...] Do mesmo modo que a magistratura e a advocacia são privilégios do bacharel em Direito, que a clínica é atividade primitiva do médico, que a construção é direito de um engenheiro, do mesmo modo o ensino secundário é área reservada ao licenciado das Faculdades de Filosofia, Ciências e Letras (INTERIORIZACÃO..., p. 7)

Do movimento provocado pela referida Fundação resultou uma vitória no campo político, embora parcial: a promulgação da Lei Estadual $n^{\circ} 1.802$ de 25 de outubro de 1962, deliberando a criação de Faculdades de Filosofia para Feira de Santana, Ilhéus, Jequié, Caetité, Vitória da Conquista e Juazeiro. Essa Lei estabelecia como objetivo "preparar professores para o magistério secundário, incrementar a pesquisa autêntica e difundir a cultura universitária no interior do Estado". (TAVARES, 1985) Assim, estava instituída pelo poder estadual a necessidade de implantação no interior do Estado de Faculdades voltadas para formação de professores, conforme demonstrado no estudo da Fundação Simões Filho.

\section{A Associação Educacional Filinto Bastos e o PIEC}

Pesquisa de Santos (2011) elucida que deputados ligados ao município de Feira de Santana protagonizaram na Assembleia Legislativa a defesa da promulgação da Lei Estadual n 1.802/62. Em razão mesmo da existência nesse município de um forte movimento pela interiorização da universidade desde o final dos anos de 1950, liderado pelo médico Geraldo Leite. Este foi o mesmo que abraçou o ideário da Fundação Simões Filho, fazia parte da diretoria dessa entidade, cujo projeto fora encampado na cidade por lideranças intelectuais e políticas, ao ponto de alcançar e sensibilizar o tecido social. Em Feira de Santana, os estudantes mobilizados pelos Grêmios estudantis e pela Associação Feirense de Estudantes Secundaristas (AFES), sindicatos, clubes de serviço, representações classistas, imprensa, formaram comitês em defesa da implantação da Universidade Rural na cidade (A Tarde, edições de 09/04/1962 e de 11/04/1962). 
(6) Às vésperas do golpe militar essa Associação assinava com a AFES, correspondência ao governador Lomanto Júnior solicitando providências para viabilizar a Faculdade de Filosofia. (Acervo particular de Fernando Pinto).

(7) No ápice das pressões internas e externas sobre a Universidade da Bahia a favor da interiorização, o Reitor Albérico Fraga, "interiorizou" a UBA através dos Seminários de Música, criando Departamentos em Itabuna e Feira de Santana, em março de 1962, quando se viu pressionado a apoiar publicamente a interiorização da universidade (Jornal da Bahia, 26 de março de 1962) Após 1964 a Universidade retirou o apoio financeiro a esses Departamentos, o de Feira de Santana fora mantido com trabalho voluntário de professores e alunos e, posteriormente, foi integrada à Universidade de Feira de Santana
Nesse sentido, a implantação da lei, que instituía as Faculdades de Filosofia, passava a ser um ponto de honra dos "feirenses" (intelectuais e parlamentares). No reconhecimento de que toda a população tem direito á educação em todos os níveis, criou-se uma entidade para viabilizar a proposta da Faculdade de Filosofia de Feira de Santana: a Associação Educacional Desembargador Filinto Bastos. Diferente da entidade anterior essa sobreviveu por mais anos: de 1963 a 1968 - acompanhou, portanto, um a conjuntura de rupturas e transições com o golpe militar. Os vínculos políticos de suas principais lideranças, que no primeiro ano de existência buscou apoio no movimento estudantil, ${ }^{6}$ a partir do golpe (ou mesmo antes) estavam mais próximos dos agentes que dariam cobertura à ditadura em Feira de Santana. Assim, a Associação Filinto Bastos teve condições de estabelecer na cidade um pólo cultural e político a favor da criação da pleiteada Universidade do interior, cuja base de lançamento seria a aludida Faculdade de Filosofia.

Concebida pelo deputado federal Wilson Falcão, após a derrocada da Fundação Simões Filho, a entidade foi liderada pelo advogado Fernando Pinto Queiroz que, por quatro anos planejou a organização da Faculdade de Filosofia de Feira de Santana. Empreitada que contaria com um dos principais agentes da Fundação Simões Filho, Geraldo Leite, que tinha vínculos orgânicos com o projeto de interiorização da universidade e com a cidade.

Planejada a Faculdade de Filosofia com o que se imaginava necessário para sua implantação, contudo faltavam-lhe recursos. Com aparente espaço na arena política estadual, pois a principal força oriunda do movimento social, os estudantes sairiam de cena e com eles o restrito apoio da reitoria da UBA, ${ }^{7}$ a Associação Filinto Bastos acionou várias frentes, vislumbradas pelas lideranças acima citados, em especial o deputado Wilson Falcão em virtude do seu trânsito político e pessoal no campo de poder. Assim, buscou-se apoio financeiro e logístico junto a entidades e órgãos, como: a Campanha Nacional de Educandários Gratuitos (CNEG), a Prefeitura municipal, entidades católicas, o Governo do Estado.

A feição ambígua da referida Associação não lhe era favorável naquela situação histórica. Vez que nascida de proposições e aspirações do movimento social, do qual não conseguira se desvencilhar por completo, em outros momentos, já na ditadura, lideranças dos estudantes e de políticos de oposição, foram chamadas a participar de caravanas para pressionar o governo estadual. Naquela con- 
juntura social e política a resolução dos problemas da população passou a ser abordado a partir de prioridades definidas de cima para baixo. Ou seja, no caminho da Associação Filinto Bastos foi interposto o PIEC sob a vigência da ditadura militar.

O PIEC foi desenvolvido pela Secretaria de Educação e Cultura da Bahia, durante a gestão de Luis Viana Filho (entre 1967-1971). Trata-se de plano mais abrangente, elaborado por especialistas na área, mas no tocante às propostas e concepções para o ensino superior não abandonaria as linhas mestras do Plandeb: subordinava a educação aos ditames do desenvolvimento econômico e mantinha o foco na questão do ensino profissionalizante. Abaixo as metas principais do PIEC:

a) atendimento prioritário das áreas vinculadas ao processo de desenvolvimento econômico, através do fortalecimento de algumas instituições existentes [sobretudo na capital];

b) implantar no interior 4 faculdades para formação de professores de primeiro ciclo;

c) Implantar Universidade do Sul do Estado. (BAHIA, 1968)

Dos movimentos da sociedade civil pela interiorização da universidade, observa-se que ele capitaliza a ideia de universidade (no Sul do Estado) e, a que mais diretamente interessa neste trabalho, e sugestão de formar professores. Com um diferencial, apenas para atuar no primeiro ciclo (antigo ginásio), através da implantação de cursos de licenciatura curta, a fim de fortalecer o ensino profissionalizante no antigo primeiro grau. Ou seja, a sugestão de tais "faculdades de formação de professores" não trazia em si, exatamente, a ideia de núcleo que precederia a implantação de universidade como queria o movimento interiorano em Feira de Santana. Pois, reconhece-se no PIEC que o ensino universitário seria responsabilidade da instância federal e o papel estadual seria meramente supletivo, complementar (p. 38). Tanto que, os recursos financeiros previstos para o ensino superior eram de apenas $2 \%$ do total de investimentos.

$\mathrm{Na}$ época a sociedade feirense encontrava-se mobilizada em prol da Faculdade de Filosofia. Procurado, o Secretário Navarro de Brito discordou de proposta do presidente da Associação "para que se firmasse um convênio entre o Estado, a Prefeitura e a Associação Educacional Filinto Bastos, o que não foi aceito pelo Secretário, alegando que o Estado tomaria para si a responsabilidade da cria- 
(8) Entrevista de Fernando P. Queiroz, concedida a uma das autoras, em fevereiro de 2009.

(9) Em 1965 a Universidade da Bahia passou a chamar-se Universidade Federal da Bahia, através d Lei $n^{\circ} 4.759$, de 20 de agosto de 1965

(10) Trata-se de artigos de José Maria Nunes Marques (2007), diretor da FEEFS, no jornal Tribuna Popular, de Feira de Santana. ção da Faculdade" - esta declaração aparece no jornal Situação, de Feira de Santana (17 de fevereiro de 1968, nº 90, p. 3), e está atribuída ao Secretário de Educação de Feira de Santana. Naquele momento, informa o citado jornal, o líder da referida Associação e o Secretário feirense, acompanhados de caravana composta por representantes da sociedade feirense, líderes estudantis, vereadores e deputados, solicitavam mais uma vez ao governo estadual a implantação da Faculdade de Filosofia de Feira de Santana. Por volta dessa ocasião, o Secretário Navarro de Brito, também professor da Universidade Federal, informaria aos líderes da entidade feirense, que "os tempos eram outros" e não mais se criavam universidades a partir de Faculdades de Filosofia, posto que essa importância, e a centralidade de formar professores, estariam no momento nas Faculdades de Educação (informação verbal). ${ }^{8}$

A Universidade da Bahia, naquele momento UFBA, ${ }^{9} \mathrm{implanta-}$ va a sua grande reforma (pensada no inicio da década, como visto, e aprofundada entre 1966-1967), e, por coincidência, instituída naquele mesmo fevereiro de 1968, por meio do Decreto Federal $n^{\circ}$ 62.241, que tratava da sua "reestruturação", quando foram criados novos institutos e a mencionada Faculdade de Educação. (UNIVERSIDADE FEDERAL DA BAHIA, 2006)

Contudo, a partir do momento em que o "Estado tomaria para si a responsabilidade da criação da Faculdade" em Feira de Santana, os feirenses, através de sua entidade, passam a reivindicar "Faculdade de Educação". Quando, então, em setembro de 1968 foi instalada a Faculdade Estadual de Educação de Feira de Santana, porém com o formato estabelecido no PIEC e não o do recém-implantado da UFBA. Artigos em defesa desta "faculdade de formação de professores", escritos por seu diretor, ${ }^{10}$ demonstram que de fato houve frustração, pois a expectativa local era de uma faculdade que fosse o alicerce inicial para universidade.

\section{Últimas considerações}

Conforme vimos, os interesses e objetivos estatais expressos nos planos de governo em matéria de ensino superior na década de 1960, aliados à própria organização do campo de ensino superior na Bahia (a UFBA, mesmo com projeto "inovador", situava-se como instituição elitista), sempre restringiram as aspirações da sociedade 
civil interiorana, que em última instância desejava uma educação de qualidade extensiva a toda população e em todos os níveis.

As decisões de política educacional do governo baiano, no período estudado, fazem parte de um conjunto maior de mudanças que transformaram o país. Contudo, as lutas no campo da educação superior na Bahia pontuam a singularidade local, que forçaria a instância estadual a assumir sozinha a interiorização desse nível até a década de 1990.

\title{
A legacy of the teacher: move internalization university in the State of Bahia
}

\begin{abstract}
This study discusses the preparation of university professors as a relevant aspect of the historical trajectory of the expansion of public higher education in the State of Bahia. The analysis is based on the State Plan for Bahian Economic Development (PLANDEB) and the Intregal Plan for Education and Culture (PIEC), as well as on documentation produced by Bahian intellectuals, especially in newspapers, The idea of professor preparation is revealed in propositions put forward by civil society regarding the interiorization of the university and also in proposals for effectuating a state public model. The methodological approach seeks to address the different dimensions of the social actors involved, considering the relations of force that circumscribe the formation of a university domain in the Bahian interior. For this purpose, the investigation examines the notion of domain, as utilized by Bourdieu, and studies the relations of force present in a given historical situation, in accordance with a concept put forth Gramsci. It can be inferred that the resistance of dominant sectors to university interiorization, allied with the concern of successive state administrations with the late industrial development of Bahia, marked the conflicts between the different conceptions of higher education that permeated the interior environment and which contained implications for the question of the preparation of university professors.
\end{abstract}

Keywords: Higher education in Bahia. Educational Policy. Social movements for education.

\section{Referências}

BOURDIEU, P. O poder simbólico. 2. ed. Rio de Janeiro: Bertrand Brasil, 1998.

. Razões práticas: sobre a teoria da ação. Tradução: Mariza Corrêa. São Paulo: Papirus, 1996.

BRITO, A. M. F. O golpe de 1964, o movimento estudantil na UFBA e a resistência à ditadura militar (1964-1968). 2008. Tese (Doutorado em História) - Faculdade de Filosofia e Ciências Humanas, Universidade Federal da Bahia, Salvador, 2008.

BAHIA. Secretaria de Educação e Cultura. Plano Integral de Educação e 
Cultura. Salvador, 1968 e 1969. (v. 1 e 2)

BAHIA. Fundação Comissão de Planejamento Econômico (CPE). Plano de Desenvolvimento do Estado da Bahia. Salvador, 1950.

GRAMSCI, A. Maquiavel, a política e o estado moderno. Rio de Janeiro: Civilização Brasileira, 1984.

GUIMARÃES, A. S. A. A formação e a crise de hegemonia burguesa na Bahia - 1930 a 1964. 172 f. Dissertação (Mestrado em Ciências sociais) - Faculdade de Filosofia e Ciências Humanas, Universidade Federal da Bahia, Salvador, 1982.

MARQUES, Z. C. N. (Org.). José Maria Nunes Marques: educar: seu trabalho, sua vida. Salvador: Vercia, 2007.

SANTOS, A. M. F. dos. Uma aventura universitária no sertão baiano: da Faculdade de Educação à Universidade Estadual de Feira de Santana. 2011. 317 f. Tese (Doutorado em Educação) - Faculdade de Educação, Universidade Federal da Bahia, Salvador, 2011.

TAVARES, L. H. D. (Coord.). Ementário da legislação Educacional do Estado da Bahia no período republicano, 1989-1983. Salvador: Instituto de Estudos e Pesquisas em Ciência, Educação e Cultura Anísio Teixeira, 1985.

TEIXEIRA, F.; GUERRA, O. 50 Anos da industrialização baiana: do enigma a uma dinâmica exógena e espasmódica. Bahia Análise e Dados, Salvador, 2000.

UNIVERSIDADE FEDERAL DA BAHIA. Pró-reitoria de Planejamento e Administração. Setor de Informação e Documentação. UFBA em Números: especial 60 anos. Salvador, 2006. Disponível em: < http:// www.proplad.ufba.br/docs/ufba_numeros_60anos.pdf > . Acesso em: 20 jun. 2011.

Recebido: 16/09/2012 | Aprovado: 15/01/2013 